\title{
AGE-DEPENDENT CHANGES IN THE PUBERTY-CONTROLLING FUNCTION OF THE MEDIAL AND CORTICAL AMYGDALOID NUGLEI
}

\author{
F, DÖCKE \\ with the technical assistance of Doris Hochbaum, \\ Barbara Hohenberg and Susanne Jonas \\ Humboldt-University, \\ Institute of Experimental Endocrinology (Charité), \\ 104 Berlin, Schumannstr. 20/21, GDR
}

\section{SUMMARY}

The puberty-controlling function of the mediocortical amygdala (MCA) was studied in the following way : the anterior or the posterior parts of the medial as well as of the cortical amygdaloid nucleus of immature female rats were bilaterally lesioned with a platinum electrode, or unilaterally implanted with a I:4 mixture of oestradiol benzoate (OB) and cholesterol at 2I, 26 or 32 days of age. In the thus obtained eight experimental groups, each subdivided into three age groups, the onset of puberty was verified by recording the dates of vaginal opening and of first ovulation and by evaluating the length of the first ovarian cycle.

The following results seemed most interesting. Bilateral lesioning of the anterior part of the medial amygdaloid nucleus (AMN) on day $2 \mathrm{I}$ induced true precocious puberty. In 26 -day-old females, damage of the posterior part of the medial amygdaloid nucleus (PMN) delayed the occurrence of the first pubertal ovulation significantly. Implantation of $O B$ at this age into the PMN or the posterior part of the cortical amygdaloid nucleus (PCN) resulted in precocious ovulation on day 32 and a significant prolongation of the first ovarian cycle. Although a distinct retardation of vaginal opening and ovulation was observed in rats that had been lesioned in both the medial amygdaloid nucleus or the PCN on day 32, different findings were obtained after implantation of $\mathrm{OB}$ at this age. Precocious ovulation and lengthening of the first ovarian cycle were recorded in rats implanted into the AMN or PMN, whereas similar implants induced a highly significant delay of the onset of puberty when placed into the anterior part of the cortical amygdaloid nucleus (ACN) or PCN.

The results suggest:

I. That the AMN has a gonadotrophin-inhibiting function at three weeks of age.

2. A site of action of the positive, ovulation-inducing oestrogen feedback develops in the posterior part of the MCA during the $4^{\text {th }}$ week of life. This oestrogen-dependent gonadotrophinstimulating activity is concentrated in the medial amygdaloid nucleus on day 32 .

3. At the same time, the cortical amygdaloid nucleus may develop to a site of action of the negative oestrogen feedback and may additionally stimulate the secretion of FSH in the presence of a low oestrogen level. 


\section{INTRODUCTION}

Studies on the puberty-controlling function of the mediocortical amygdala (MCA) were initiated by ElLERS and CRITChLow (I96o, I96I) who reported that bilateral lesioning of this limbic region or of the stria terminalis in female rats at about three weeks of age induced precocious puberty, and concluded that the MCA inhibits gonadotrophin secretion before puberty. However, the findings of these authors were not confirmed by later investigations. A puberty-delaying effect of amygdaloid lesions produced in 4-day-old female rats was described by RELKIN (I97I), and BLOCH and GANONG (I97I) found a slight retardation of puberty after bilateral damage of the mediocortical or basolateral amygdaloid nuclei at 2 I-23 days of age. Comparing the effects of lesions made with platinum and stainless-steel electrodes, VELASCO (1972) reached the conclusion that the amygdala has a stimulating effect on gonadotrophin secretion in prepubertal female rats that is abolished by platinum lesions and increased by the irritative effect produced by metallic deposit in electrochemical lesions.

In a recent paper (DöckE, I974) it was reported that the effect on puberty of damage of the MCA in immature female rats may depend on the localization of the lesions within this nuclear complex. Whereas bilateral platinum lesions placed in the anterior region (AMCA) at 22 days of age induced true precocious puberty, similar lesions were ineffective when located more caudally in the MCA (PMCA). The data indicated that the AMCA, but not the PMCA exerts a gonadotrophininhibiting function at this age. Investigating the influence of amygdaloid lesions produced at different ages on the onset of puberty in female rats, DöKE, LEMKE and OKRASA ( 1976 ) found that the gonadotrophin-inhibiting activity of the AMCA vanishes during the fourth week of life, and that, simultaneously, a gonadotrophinstimulating activity develops in the posterior part of the MCA. As was shown by intra-amygdaloid implantation of oestrogen, this activity is related to the positive oestrogen feedback and can also be demonstrated in the AMCA at 32 days of age.

In the present study, experiments were performed in immature female rats to localize more exactly the gonadotrophin-controlling functions exerted by the MCA at different ages.

\section{MATERIALS AND METHODS}

Female Wistar rats were obtained from the breeder when 20 days old. They were fed a standard diet and housed in an air-conditioned room artificially lighted from 05.00 to $19.00 \mathrm{~h}$.

Vaginal opening (VO) was recorded daily between 08.00 and $09.00 \mathrm{~h}$, and vaginal smears were taken with a rounded glass rod from the day of VO till autopsy. To establish the occurrence of the first ovulation, laparotomies were performed by the dorsal route and the ovaries inspected for corpus luteum formation after each oestrous period until corpora lutea were found. The day of the preceding vaginal oestrus or, if cornification lasted for more than one day, the last day a cornified smear was recorded, was designated the day of ovulation. If a metoestrous smear was found on the day of VO, ovulation was considered to have taken place on the day before VO. In the strain of rats used, VO and the first ovulation generally occur between 37 and 42 days of age. 
Bilateral lesions of the anterior or posterior parts of the medial or cortical amygdaloid nucleus were produced by passing anodal DC of $1.0 \mathrm{~mA}$ for $4 \mathrm{sec}$ through a unipolar platinum electrode, o.12 $\mathrm{mm}$ in diameter and glass-insulated to within $0.3 \mathrm{~mm}$ of its tip. Sham-lesioned females were bilaterally implanted with the electrode, but no current was passed.

Implants for unilateral implantation of oestradiol benzoate (OB) were prepared by heating a $I: 4$ mixture of $O B$ and cholesterol to just above the melting point and drawing it into the tips of calibrated glass capillary tubes with an inner diameter of $0.2 \mathrm{~mm}$. The tubes were scraped and cleaned on the outside with ether under a dissecting microscope. Cholesterol implants prepared in the same way were used in the controls. After unilateral introduction into the brain each capillary was fixed to the skull with dental cement and removed $48 \mathrm{~h}$ after placement. To minimize brain damage at removal, the lightly anaesthetized rats were fixed in the stereotaxic apparatus, and the cement was loosened with a scalpel and lifted cautiously with tweezers.

All lesions and implantations were done under ether anaesthesia, the rats being fixed in a Horsley-Clarke stereotaxic instrument. The following coordinates, in millimeters, were employed for lesions and implantations in $2 \mathbf{r}$-day-old females, the first number indicating the distance posterior to the bregma, the second the distance lateral to the midline and the third the depth from the surface of the skull : anterior part of the medial amygdaloid nucleus (AMN) - r.I, $\pm 2.5,-8.7$; anterior part of the cortical amygdaloid nucleus (ACN) - I.I, $\pm 3.0,-8.7$; posterior part of the medial amygdaloid nucleus $(\mathrm{PMN})-2.0, \pm 2.5,-8.6$; posterior part of the cortical amygdaloid nucleus $(\mathrm{PCN})-2.0, \pm 3 . \mathrm{I},-8.8$. The coordinates were slightly modified for stereotaxic operations performed at 26 or 32 days of age. The vertical and horizontal diameters of the lesions were between 0.5 and $0.8 \mathrm{~mm}$.

Autopsy was performed on the day of vaginal oestrus that followed the first pubertal ovulation. The oviducts were removed, squeezed between two slides, and examined for the presence of ova under a dissecting microscope. Rats in which tubal eggs could not be found were excluded from the evaluation. The brains were removed and fixed in ro p. roo formalin. To check the localization of lesions and implants, frozen serial sections (I5 $\mu \mathrm{m}$ ) were cut transversely and stained with haematoxylin and eosin.

The results were statistically analysed by Student's $t$-test.

\section{RESULTS}

Immature female rats were bilaterally lesioned in the AMN, ACN, PMN, or PCN at $2 \mathrm{r}, 26$ or 32 days of age. The date of VO was recorded, and the occurrence of the first ovulation was established by laparotomy. The rats were autopsied on the day of the next vaginal oestrus and the oviducts examined for the presence of ova to verify the duration of the first ovarian cycle. Table $I$ shows that lesioning of the AMN on day $2 \mathrm{I}$ induced true precocious puberty as characterized by advancement of VO and ovulation to day 34 and a normal duration of the first ovarian cycle. In comparison with the corresponding sham-lesioned controls, damage of the PMN or the cortical amygdaloid nucleus did not influence the onset of puberty.

The puberty-accelerating effect of lesions placed into the AMN was not obtained in rats that were 26 days old at the time of surgery. At this age, however, lesioning of the PMN delayed the occurrence of the first pubertal ovulation significantly without influencing the date of VO or the length of the first ovarian cycle. Damage of the cortical amygdaloid nucleus did not change the onset of pubertal events.

In 32-day-old rats, retardation of VO and of the first ovulation was induced by lesions localized in the AMN, PMN or PCN, but not in the ACN. The occurrence of ovulation was maximally delayed : to $47.3 \pm 3.47$ days of age and, additionally, the first ovarian cycle prolonged to $9.4 \pm 2.22$ days, in rats that had been lesioned in the AMN.

To study the relationships between oestrogen and the gonadotrophin-controlling function of the MCA, $\mathrm{OB}$ and cholesterol or cholesterol alone was unilaterally 


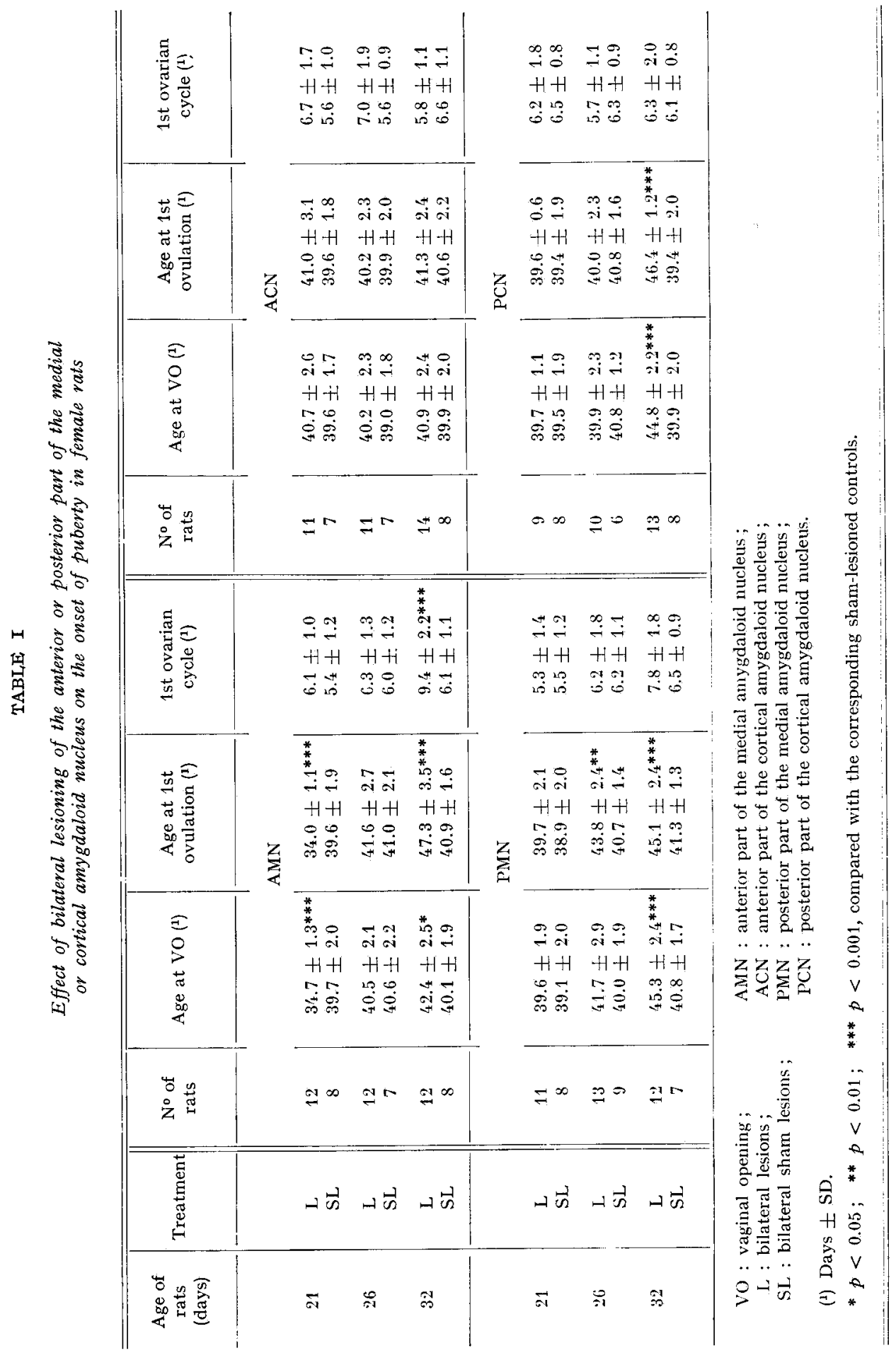


MEDIOCORTICAL AMYGDAIA AND FEMALE PUBERTY
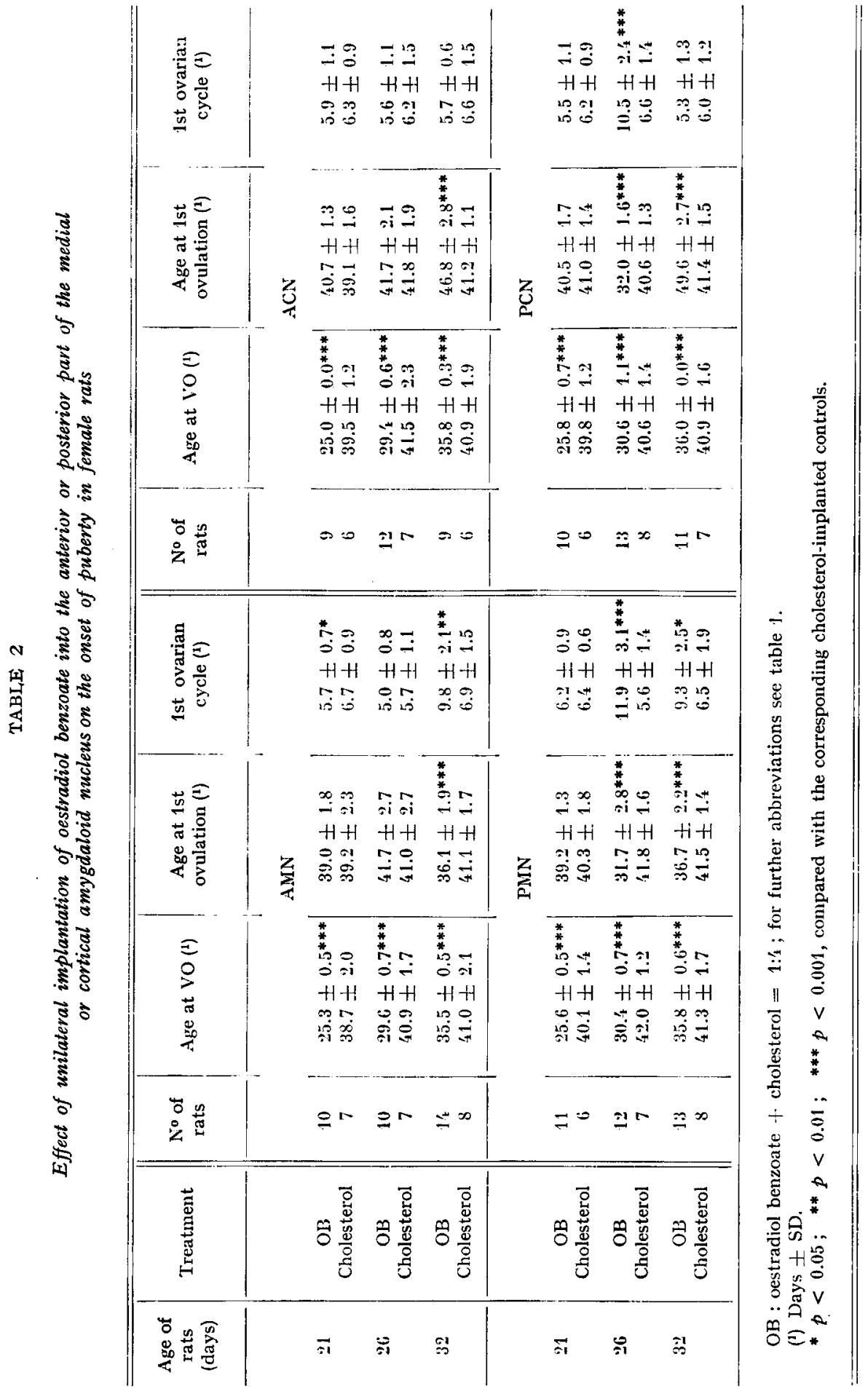
implanted into the anterior or posterior parts of the medial or cortical amygdaloid nucleus of female rats at $2 \mathrm{I}, 26$ or 32 days of age. The onset of puberty was evaluated as described above (table 2). Implantation of $\mathrm{OB}$ induced rupture of the vaginal membrane after 3-5 days irrespective of the site of implantation and age of rats. This precocious VO was not accompanied by ovulation when the oestrogen was introduced on day $2 \mathrm{I}$. Rather, first ovulation occurred at about 40 days of age, i.e. at the time when VO and the first ovulation were recorded in the controls implanted with cholesterol.

OB placed into the AMN or ACN on day 26 did not influence the date of the first ovulation either. However, localization of the oestrogen in the PMN or PCN induced a highly significant advancement of first ovulation. It occurred shortly after $\mathrm{VO}$, i.e. at about 32 days of age, and was followed by a significantly lengthened first ovarian cycle, so that the second ovulation was delayed to the time of spontaneous onset of puberty.

A similar result was obtained after implantation of OB into the AMN or PMN on day 32. Precocious ovulation was recorded at about 36 days of age, and the length of the first ovarian cycle was distinctly increased. In contrast to these findings, implants located in the $\mathrm{ACN}$ or $\mathrm{PCN}$ induced a highly significant retardation of the first ovulation which took place on days 47 and 49 , respectively. The duration of the first ovarian cycle was not changed in these rats.

A further finding may be worth-while mentioning. Following implantation of $\mathrm{OB}$ into the AMN on day 2I, 8 out of I7 females showed persistent vaginal cornification between VO and ovulation, i.e. for almost two weeks, although the implants had been removed $48 \mathrm{~h}$ after placement. Oestrogen localized in the ACN, PMN or PCN did not induce this effect, nor did cholesterol implants placed into the AMN. Persistent vaginal oestrus was also observed in part of the rats after implantation of $\mathrm{OB}$ into both the $\mathrm{AMN}$ (40.0 p. IOo) or $\mathrm{ACN}$ (35.3 p. I00) at 26, but not at 32 days of age.

\section{DISCUSSION AND CONCLUSIONS}

The present results confirm recent findings on different gonadotrophin-controlling functions of the AMCA and PMCA in immature female rats (DöckE, I974; Döcke, I EMKE and OKRASA, I976). It could be demonstrated that a pubertydelaying action of the AMCA at three weeks of age, indicated by the acceleration of puberty following destruction of this area (DöckE, I974), may be restricted to the AMN. This is in good agreement with the data obtained by ELWERS and CRITCHLow (I960) after bilateral electrolytic lesioning of the amygdala in I8 to 20-dayold female rats. The authors reported that advancement of puberty resulted from damage of the medial amygdaloid nucleus and medial part of the basal amygdaloid nucleus. To judge from the illustrations the effective lesions involved the rostral half of these nuclei. Lesions located more laterally or in the most posterior part of the amygdala were ineffective.

On the other hand, lesions made with platinum electrodes in the medial amygdaloid nucleus of $20-$ to 24 -day-old female rats did not induce precocious puberty 
in the studies of BLOCH and GANONG (I97I), VELASCO (I972). There was even a delay in the occurrence of VO. However, the authors, did not indicate the posterior extension of tissue destruction. It was recently reported (DöckE, I974) and confirmed in the present experiments that only lesions restricted to the anterior part of the MCA or medial amygdaloid nucleus accelerate the onset of puberty. Furthermore, the rats employed in both studies attained spontaneous puberty about one week earlier than ours, so the experimental conditions may not have been comparable.

Surprisingly enough it is the medial amygdaloid nucleus which has a gonadotrophin-stimulating activity at later ages. This activity seems to be related to the oestrogen-dependent ovulatory gonadotrophin secretion. Lesioning of the PMN on days 26 or 32 delayed the first pubertal ovulation significantly. On the other hand, precocious ovulation was induced by implantation of $\mathrm{OB}$ into the PMN at 26 or 32 days of age. Several studies (ZARRow and Quins, I963; McCormack and Meyer, I964 ; YING and GREEP, I97I ; CALIGARIS, ASTrada and TALEISNIK, I972) suggest that the neurohormonal mechanism for the positive oestrogen feedback develops in female rats during the fourth week of life. The present results indicate that the establishment of the oestrogen-dependent gonadotrophin-stimulating function in the medial amygdaloid nucleus coincides with that of the positive feedback mechanism. However, the maturation of this amygdaloid function seems to proceed further. Whereas OB implants localized in the PMN were effective at 26 and 32 days of age, implantation into the AMN resulted in precocious ovulation only in 32-day-old females. An ovulatory reaction to the introduction of oestrogen into both the AMCA and PMCA (DöckE et al., I975) or AMN and PMN (unpublished data) was also observed in adult female rats, so that the entire medial amygdaloid nucleus may represent a site of action of the positive oestrogen feedback from the prepubertal period through adult life. Its oestrogen-dependent stimulatory activity may participate in the control of puberty, because bilateral damage on days 26 or 32 delayed the occurrence of the first pubertal ovulation significantly. In 32-dayold rats, VO too was retarded. However, the ovulatory oestrogen effect mediated by the medial amygdaloid nucleus is not tantamount to the induction of precocious puberty, because significant lengthening of the first ovarian cycle was recorded in oestrogen-implanted rats with precocious ovulation. The results support the assumption of DöCKE and DöRNER (I974) that the positive, ovulation-inducing oestrogen feedback, and the acceleration of sexual maturation by oestrogen as described by RAMIREZ and SAWYER (I965), are based on different neurohormonal mechanisms.

An explanation for the induction of persistent vaginal cornification by oestrogen implanted into the AMN at 2 I or the AMN or ACN at 26 days of age requires further exploration, but a stimulation of gonadotrophin secretion is indicated by these findings. The preliminary conclusion may be drawn that the gonadotrophininhibiting activity exerted by the AMN at three weeks of age may not only be abolished by destruction of this nuclear compartment, but may also be diminished by a high local oestrogen concentration, although advancement of puberty is not induced in this way.

The cortical amygdaloid nucleus may not have a specific gonadotrophincontrolling function in $2 \mathrm{I}$-day-old rats. Neither bilateral lesions nor implantation of $\mathrm{OB}$ caused significant changes in the onset of puberty or vaginal cyclicity. At 
26 days of age, a functional adjustment to the medial amygdaloid nucleus seems to take place, because $O B$ induced persistent vaginal oestrus after implantation into the anterior, and precocious ovulation after placement into the posterior parts of both nuclei. The retardation of puberty recorded after bilateral lesioning of the medial amygdaloid nucleus as well as the PCN indicated that a similar situation exists in 32-day-old rats. However, a significant delay of the first ovulation was observed after implantation of $\mathrm{OB}$ into the $\mathrm{ACN}$ or $\mathrm{PCN}$, whereas implants localized in the AMN or PMN induced precocious ovulation. This finding suggests that the puberty-delaying effect of bilateral lesions in the PCN was not due to the removal of an oestrogen-dependent gonadotrophin-stimulating activity. It may rather be assumed that an effect similar to that described by SMITH et al. (I97I) and SMITH and Lawtox (1972) in cyclic female rats was obtained in these animals. SMITH and coworkers reported that bilateral damage of the cortical amygdaloid nucleus inhibited completely the compensatory ovarian hypertrophy after hemiovariectomy and suppose that this was due to an inhibitory influence on FSH secretion.

A further assumption to be derived from the results may be that the cortical amygdaloid nucleus develops to a site of action of the negative oestrogen feedback during the fifth week of life. However, the findings obtained in adult female rats after both implantation of oestrogen into the MCA or cortical amygdaloid nucleus

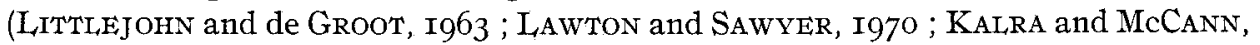
I972; DöcKE et al., I975) and stimulation or lesioning of this region or the stria terminalis (BUNN and EVERETT, I957 ; VeLASCO and TALEISNIK, I969, I97I ; KAWAKami, Terasawa and IbUKI, I970 ; Veiasco, I972 ; KaWakami $e t$ al., I973) strongly suggest that after puberty the MCA exerts mainly a gonadotrophin-stimulating activity in the presence of a high oestrogen level. A possible explanation for this difference between prepubertal and postpubertal females may be offered by the supposition that a change of function takes place in the cortical amygdaloid nucleus at the time of puberty. An upward shift in the threshold for inhibition of gonadotrophin secretion by oestrogen has been considered an essential part of the mechanisms that lead to the onset of puberty (HOHLWEG, I936 ; McCANN and RAMIREz, I964; Donovan and Van Der WerfF ten Bosch, I965; Critchlow and BarSELA, 1967). Further studies are necessary to see if the cortical amygdaloid nucleus participates in this process.

Sexual Maturation 3rd Workshops August 31, September 3, 1975.

\section{RÉSUMÉ́}

MODIFICATIONS ÂGE-DÉPENDANTES DE LA FONCTION DE CONTRÔLE DE LA PUBERTÉ DES NOYAUX MÉDIAN ET CORTICAL DE L'AMYGDALE

Le rôle de l'amygdale médiocorticale (MCA) dans le contrôle de la puberté a été étudié selon le protocole suivant : des Rattes immatures sont soumises à une lésion bilatérale avec une électrode de platine ou reçoivent un implant contenant un mélange $\mathrm{r}: 4$ de benzoate d'estradiol (OB) et de cholestérol dans les parties antérieure et postérieure des noyaux médian et cortical de l'amygdale, à $2 I, 26$ ou 32 jours. L'apparition de la puberté est définie par le jour de l'ouverture vaginale, le jour de la première ovulation et la durée du premier cycle ovarien. 
La lésion bilatérale de la partie antérieure du noyau médian de l'anygdale (AMN) au jour 2 I induit une puberté précoce vraie. Chez les Rattes de 26 jours, la lésion de la partie postérieure du noyau médian de l'amygdale (PMN) retarde significativement la première ovulation. L'implant de $\mathrm{OB}$ au même âge dans le PMN ou la partie postérieure du noyau cortical de l'amygdale (PCN) entraîne une ovulation précoce le jour 32 et un allongement significatif du premier cycle ovarien. On observe un net retard de l'ouverture vaginale et de l'ovulation chez les Rattes qui ont subi une lésion du noyau médian de l'amygdale ou le PCN à 32 jours. Après implant de OB au même âge, on observe une ovulation précoce et un allongement du premier cycle ovarien chez les Rattes recevant un implant dans AMN ou PMN et un retard hautement significatif de l'apparition de la puberté chez les Rattes recevant un implant dans la partie antérieure du noyau cortical de l'amygdale (ACN) ou PCN.

Ces résultats suggèrent que :

I. L'AMN a une fonction d'inhibition des gonadotropines chez la Ratte de 3 semaines.

2. Un site d'action de la rétroaction positive des estrogènes induisant l'ovulation se développe dans la partie postérieure du MCA au cours de la $4^{\mathbf{e}}$ semaine. Cette activité de stimulation des gonadotropines, estrogène-dépendante, est localisée dans le noyau médian de l'amygdale au jour 32 .

3. Au même moment, le noyau cortical de l'amygdale doit se transformer en un site d'action de la rétroaction négative des estrogènes et doit de plus stimuler la sécrétion de FSH en présence d'un faible niveau d'estrogènes.

\section{REFERENCES}

BLOCH G. J., GANoNG W. F., I971. Lesions of the brain and the onset of puberty in the female rat. Endocrinology, 89, 898-901.

Bunn J. P., Everett J. W., 1957. Ovulation in persistent-estrous rats after electrical stimulation of the brain. Proc. Soc. exp. Biol. Med., 96, 369-37r.

Caligaris L., Astrada J.J., Taleisnik S., r972. Influence of age on the release of luteinizing hormone induced by oestrogen and progesterone in immature rats. J. Endocr., 55, 97-103.

Critchlow V., Bar-Sela M. E., I967. Control of the onset of puberty, Ior-I62, in : Martini L., Ganong W. F., Neuroendocrinology, 2, Academic Press, New York and London.

Döcke F., I974. Differential effects of amygdaloid and hippocampal lesions on female puberty. Veuroendocrinology, 14, 345-350.

Döcke F., Dörner G., r974. Oestrogen and the control of gonadotrophin secretion in the immature rat. J. Endocr., 63, 285-298.

Döcke F., Lemke M., OKrasa R., 1976. Studies on the puberty-controlling function of the mediocortical amygdala in the immature female rat. Neuroendocrinology (in press).

Döcke F., Smollich A., Rohde W., Okrasa R., Dörner G., I975. Studies on extrahypophyseal sites of estrogen action in the induction of ovulation in rats. Endokrinologie, 65, 274-287.

Donovan B. T., Van der Werff ten Bosck J.J., I965. Physiology of puberty. Edward Arnold, London.

Elwers M., Critchlow V., rg6o. Precocious ovarian stimulation following hypothalamic and amygdaloid lesions in rats. Amer. J. Physiol., 198, $3^{81-385 .}$

Elwers M., Critchlow V., r96r. Precocious ovarian stimulation following interruption of stria terminalis. Amer. J. Physiol, 202, 281-284.

Hohlweg W., 1936. Der Mechanismus der Wirkung von gonadotropen Substanzen auf das Ovar der infantilen Ratte. Klin. Wschr., 15, I832-I835.

KalRA P. S., MCCANN S. M., 1972. Effect of CNS implants of ovarian steroids on gonadotropin release. IVth Int. Congr. Endocrinol., Excerpta Medica ICS, 256, Ir8 (Abstr.).

Kawakami M., Terasawa E., IbuKI T., I970. Changes in multiple unit activity of the brain during the estrous cycle. Neuroendocrinology, 6, 30-48.

Kawakami M., Terasawa E., Kimura F., Wakabayashi K., 1973. Modulating effect of limbic structures on gonadotropin release. Neuroéndocrinology, 12, I-I6.

LAwToN I. E., SAwYer C. H., I97o. Role of amygdala in regulating LH secretion in the adult female rat. Amer. J. Physiol., 218, 622-626.

Litrlejohn B. M., de Groot J., r963. Estrogen sensitive areas in the rat brain. Fed. Proc., 22, 57 I (Abstr.).

MCCANN S. M., RAmiRez V.D., I964. The neuroendocrine regulation of hypophyseal luteinizing hormone secretion. Recent Progr. Hormone Res., 20, 131-17o.

McCormack C. E., Meyer R. K., I964. Minimal age for induction of ovulation with progesterone in rats : evidence for neural control. Endocrinology, 74, 793-799. 
Ramirez V. D., SAWYer C. H., 1965. Advancement of puberty in the female rat by estrogen. Endocrinology, 76, II 58-I 68 .

ReLKin R., 1971. Relative efficacy of pinealectomy, hypothalamic and amygdaloid lesions in advancing puberty. Endocrinology, 88, 4r5-418.

Smith S. W., Adaniya J., Gorski M., Lawton I. E., I97I. Absence of the ovarian compensatory response in rats with lesions in the cortical amygdaloid nucleus and stria terminalis. Fed. Proc., 30, 253 (Abstr.).

Smith S. W., Lawton I. E., 1972. Involvement of the amygdala in the ovarian compensatory hypertrophy response. Neuroendocrinology, 8, 228-234.

VELASco M. E., I972. Opposite effects of platinum and stainless-steel lesions of the amygdala on gonadotropin secretion. Neuroendocrinology, 10, 301-308.

Velasco M. E., Taleisnik S., Ig69. Release of gonadotropins induced by amygdaloid stimulation in the rat. Endocrinology, 84, $132-139$.

Velasco M. E., Taleisnik S., I97x. Effects of the interruption of amygdaloid and hippocampal afferents to the medial hypothalamus on gonadotrophin release. J. Endocr., 51, 4I-55.

YING S.-Y., GreEP R. O., I97r. Effect of age of rat and dose of a single injection of estradiol benzoate $(\mathrm{EB})$ on ovulation and the facilitation of ovulation by progesterone (P). Endocrinology, 89, 785-79o.

ZARRow M. X., QuiNN D. L., I963. Superovulation in the immature rat following treatment with PMS alone and inhibition of PMS-induced ovulation. J. Endocr., 26, I8I-I 88. 